\title{
Representation of Ethnicity in Lexicographic Discourse
}

\author{
Nataliia I. Melnyk ${ }^{1}$, Iryna O. Biletska ${ }^{2}$, Oksana A. Ponomarova ${ }^{3}$, \\ Alina V. Buranova4 ${ }^{4}$ \& Alla O. Davydenko ${ }^{1}$ \\ ${ }^{1}$ Foreign Philology Department, National Aviation University, Kyiv, Ukraine \\ ${ }^{2}$ Department of Foreign Languages Theory and Practice, Pavlo Tychyna Uman State \\ Pedagogical University, Uman, Ukraine \\ 3Department of English and Methods of its Teaching, Pavlo Tychyna Uman State \\ Pedagogical University, Uman, Ukraine \\ ${ }^{4}$ Department of Foreign Languages Methodology, National Pedagogical Dragomanov \\ University, Kyiv, Ukraine \\ E-mail:nata-melnyk@uohk.com.cn
}

\begin{abstract}
In the modern world, which is characterised by migration processes, ethnic and cultural mixing, the interest of representatives of various fields of knowledge to the category of ethnicity, ethnic processes, their historical, cultural, philosophical and linguistic component is growing. In this regard, the work is devoted to studying the dynamics of representations of ethnicity in different types of discursive practices and identifying the specifics of conceptualisation of ethnicity in English-speaking society in the context of ideological, socioeconomic and socio-cultural transformations of the second half of the $20^{\text {th }}$ - early $21^{\text {st }}$ century. The relevance of the study is due to the inclusion of the dynamics of language development and change in such areas of modern linguistics as ethnolinguistics, linguocultural studies and discourse analysis, as well as growing interest in the evolution of language, lexical structure of English and changes in the English world picture with the development of ethnic culture, the synthesis of language modifications in the context of global sociocultural transformations. The following methods were used in the work: definition analysis; comparative analysis; quantitative analysis; analysis-discourse; hypothetical-deductive method; generalisation; systematisation. The research methods used in the article made it possible to substantiate the principles of material selection for studying the dynamics of ethnic representations in English dictionaries; to reveal the concepts of ethnic stereotype and ethnonym-nickname as ways of stereotyping; to characterise the concept of political correctness as relevant for the study of linguistic construction of ethnicity. The dynamics of the representation of ethnicity in the lexicographic discourse on the material of British dictionaries of two times cross-sections (mid-20 ${ }^{\text {th }}$ century and modern latest edition) in the context of socio-cultural transformations were analysed. The practical value of the work is that the obtained results contribute to a fuller understanding of the English-language picture of the world, deepen scientific ideas about the interaction of ideology, language, culture.
\end{abstract}

Keywords: ethnic stereotype, lexicographic discourse, ethnolinguistics, ethnonym, lexical structure of language.

(c) AesthetixMS 2021. This Open Access article is published under a Creative Commons Attribution Non-Commercial 4.0 International License (http://creativecommons.org/licenses/by-nc/4.o/), which permits non-commercial re-use, distribution, and reproduction in any medium, provided the original work is properly cited. For citation use the DOI. For commercial re-use, please contact editor@rupkatha.com. 


\section{Introduction}

The formation of the category of ethnicity in its modern sense begins in the second half of the $2 \mathrm{O}^{\text {th }}$ century. In modern humanities, the concepts and theories of ethnic identity are grouped into two groups based on methodologically opposite approaches to the problem of ethnic substance: ontological (primordialist or essentialist) and functional (constructivist, instrumentalist) (Rybakov, 1998). The ontological approach assumes the presence of an ethnic substance that has a primordial, i.e. original nature - either sociobiological or evolutionary-historical. Proponents of the sociobiological trend interpret ethnicity as an objective fact, the original characteristic of humanity and believe that the awareness of group affiliation is embedded in the genetic code and is a product of early human evolution (Tishkov, 2003). Proponents of the ontological approach tend to view ethnic associations as real and long-standing groups with their own attributes, and consider ethnicity to be a conservative force that preserves the mentality and behaviour of previous generations.

A functional approach that combines constructivism and instrumentalism is characterised by the denial of ethnic substance. Constructivists tend to look at the external functional connections that arise in society in relation to the ethnic. According to the constructivist concept, ethnicity is not an essentialist (essential) category, but a mental construct, an "imposed" sociality, which is rooted in myths, values, symbols, created by society and constantly changing. Accordingly, ethnicity appears as a historical quantity that contains nothing static and always assumes a new meaning. Thus, everything related to identity and ethnicity has always been a construct, a figurative essence, and is essentially the result of cultural imagination and construction (Grosheva, 2006). The work is performed in line with the modern socio-constructivist paradigm, according to which the construction of ethnicity in different types of English-language discursive practices corresponds to the basic principles that characterise the development of modern socio-constructivist paradigm: interpretation of language as a social practice; the concept of language as a mobile resource, background and tool for constructing social reality and relationships; recognition of the historicity and ideology of ethnicity, its social and cultural conditionality.

Nowadays, ethnicity is studied within the framework of various linguistic areas ethnolinguistics, ethnopsycholinguistics, linguacultural studies, sociolinguistics, ethnonymy, and others. Despite the growing interest of domestic linguistics in the problems of ethnicity, the use of language as a means of ideological influence and the construction of social reality, the diachronic aspects of the representation of ethnicity have not been studied. Of particular interest is the study of ethnicity in dynamic synchrony in the context of accelerating the dynamics of social, economic and cultural life of mankind in the era of globalisation and the associated dynamics of language development and change. The relevance of the study is also due to its inclusion in such areas of modern linguistics as ethnolinguistics, linguacultural and discourse analysis, which are developing, as well as growing interest in the evolution of language, development of English vocabulary and changes in the English world picture in relation to the development of ethnos culture, synthesis of language modifications in the context of global socio-cultural transformations.

The purpose of the study is to identify the dynamics of ethnic representations in English and the description of lexical (lexicographic) and discursive means of creating ethnic meanings, taking into account the changing ideology (movement from ethnocentrism to multiculturalism). The purpose of the study led to the implementation of the following tasks:

1. To describe the main methodological approaches to the study of ethnicity and justify the relevance of the appeal to the constructivist paradigm in the study of ethnicity in language. 
2. To give a linguistic substantiation of ideological and historical ethnicity as a socio-cultural construct.

3. To select and systematise ethno-relevant lexicographic means of constructing ethnicity in English with an emphasis on the dynamics of ethnic representations in English.

4. To identify and describe the language tools involved in the conceptualisation of ethnicity in English-speaking society.

The object of research is the representation of ethnicity in English discursive practice (lexicography). The subject of research - system-linguistic (lexical) and discursive means of creating ethnic representations in English (on the material of different time slices).

\section{Materials and Methods}

In accordance with the goals and objectives, the study was conducted in two stages, each of which structurally corresponds to one section. At the first stage, the choice of the methodological concept of the study is substantiated, within the framework of which the constructivity of ethnicity as a parameter of social identity was recognised and its close connection with ideology and culture was postulated. In the analysis of works on the problems of ethnicity, it was found that ethnicity in linguistics is studied in close connection with the complex of sciences, while in domestic linguistics mainly develop etymological and dialectological areas, when in foreign linguistics more attention is paid to issues of constructing social and ethnic identity in a multicultural society. The principles of material selection for studying the dynamics of ethnic representations in English dictionaries were substantiated; the notions of ethnic stereotype and ethnonym-nickname as ways of stereotyping were revealed; the concept of political correctness was characterised as relevant for the study of linguistic construction of ethnicity.

At the second stage of the research, the dynamics of ethnic representation in lexicographic discourse on the material of British dictionaries of two-time cross-sections (mid-20 ${ }^{\text {th }}$ century and modern latest edition) in the context of socio-cultural transformations were analysed. The results show the impact of globalisation on the change of the English-speaking world and the transition from ethnocentric to multi-ethnic ideology, which is expressed in a threefold increase in the number of ethno-labelled tokens in the dictionary and illustrative examples of Oxford Advanced Learner's Dictionary of current English (Hornby, 2010) and twofold increase of names of nonEuropean nations and ethnic minorities. The fivefold increase in the number of hybrid ethnonyms (ethnohybrids) in the modern dictionary reflects the current social processes of dispersion of the world, and the high density of the American lexicographic field can be seen as a discursive signal of global Americanisation.

The research material was the dictionary articles and illustrative contexts of two editions of the dictionary A.S. Hornby: Advanced Learner's Dictionary of Current English (Hornby, 1963) and Oxford Advanced Learner's Dictionary of Current English (Hornby, 2010); selection of contexts with tokens ethnic and ethnicity. Depending on the specific stage and objectives of the study, the following methods were used: definition analysis; comparative analysis; quantitative analysis; discourse analysis; hypothetical-deductive method; generalisation; systematisation. The research was conducted by the method of continuous sampling from the dictionary of tokens that are ethnonyms and ethnonyms-deriving adjectives, as well as the analysis of illustrative contexts (IC) of dictionaries in which these tokens occur. The authors took into account those IC that either have an anthroponomic reference, or are related to human life and culture, sports, economics, politics, 
etc. The tokens in the ALDCE dictionary were considered and researched, which, in addition to the ethnic component, also have a reference to military topics, a religious reference, a social/caste reference, and a professional reference (often with a clear gender component).

The study also took into account all the words in the definitions of which used ethnonyms and ethnonyms-deriving adjectives, including lexical units denoting cultural artefacts, wordsrealities, names of clothes, culinary dishes, customs, traditions and other ethno-marked tokens, correlated with the concept of culture. The analysis of features of conceptualisation of ethnicity in dictionaries of two-time sections was carried out to reveal of the basic tendencies of development of those fragments of the English-speaking picture of the world which are connected with a phenomenon of ethnicity. The analysis of ethno-labelled tokens in the dictionary and illustrative contexts of ALDCE revealed a number of features related, in particular, to the ratio of the names of representatives of European and non-European nations and ethnic groups.

\section{Results}

To identify the dynamics of ethnic representation in lexicographic discourse, a study was conducted on the material of dictionaries The Advanced Learner's Dictionary of Current English (Hornby, 1963) and Oxford Advanced Learner's Dictionary of Current English (OALD) (Hornby, 2010). As the analysis showed, the formation of the category of ethnicity in its modern sense begins in the second half of the $2 \mathrm{O}^{\text {th }}$ century. Prior to this, the token ethnicity was not recorded in English dictionaries, although the ALDCE dictionary found 6 tokens with the component ethn-: ethnic / ethnical - of races (the races of mankind), ethnography, ethnology, ethnologist, ethnological. Ethnicity in this period is understood from an essentialist standpoint - as unchanging, due to biological (origin), intrinsic quality of man. In the following years, this understanding changed.

Ethnonyms and ethnonyms-deriving adjectives used to denote European nations and ethnic groups are represented in the sample material of the ALDCE by 54 tokens: American, Briton, British, Canadian, Czech, Czechoslovak, Cyprian, Cypriot, Dane, Danish, Dutch, Dutchman, English, Finn, French, Frenchman, German, Greek, Grecian, Hebrew, Hebraic, Irish, Irishman, Irishwoman, Italian, Jugoslav, Jew, Jewess, Jewish, Levantine, Magyar, Maltese, Netherlander, Norwegian, North countiyman, Pole, Polish, Portuguese, Romany, Russian, Scandinavian, Scot, Scotch, Scotchman, Scotchwoman, Sicilian, Slav, Slavonic, Spaniard, Spanish, Swede, Swedish, Swiss, Welsh. Among them are the names of representatives of non-existent nationalities: Jugoslav, Czechoslovak. To the same group, in the authors' opinion, it is appropriate to include the ethnonyms American and Canadian on the basis of their linguistic and civilizational community. The names of non-European nations and ethnic groups are represented in the ALDCE dictionary by 35 tokens: Arab, Bedouin, Bushman, Ceylonese, Chinese, Egyptian, Eskimo, Gypsy, Hindu / Hindoo, Indian, Japanese, Javanese, Libyan, Malay, Malaysian, Maori, Mongol, Moor, Moorish, Nipponese, Pakistani, Peruvian, Red Indian, Semite, Semitic, Sudanese, Syrian, Siamese, Sinhalese, Tamil, Tibetan, Thai, Turk, Turkish, Zulu.

Thus, in the ALDCE dictionary, the number of tokens denoting the ethnic groups of Europe and North America is 1.5 times higher than the number of tokens denoting the representatives of Africa, Asia, Oceania and Latin America. A similar situation occurs in the IC of the dictionary, where the quantitative advantage is 3.2 times ( 81 and 25 uses, respectively), with European nations represented by 21 different tokens in 81 different IC: American, British, Dutch, English, Englishman, French, German, Greek, Irish, Italian, Jewish, Jew, Polish, Portuguese, Saxon, Scot, Scotch, Spanish, Swedish, Swiss, Welsh, at that time, name the non-European nations and ethnic groups fixed in the 
number of 11 new lexemes in 25 IK: Arab, Chinese, Gypsy, Indian, Jamaican, Japanese, Mexican, Mongol, Mongolian, Moor, Peruvian.

In the authors' opinion, this ratio can be seen as a manifestation of the tendencies of ethnocentrism and Eurocentrism, as well as a low degree of interest in the problems of the multicultural world in the English-speaking society of the historical period. In addition, the ALDCE dictionary presents ethnonyms and ethnonyms-deriving adjectives that can be attributed to the group of words-historicisms (only 11 tokens), for example: Anglo-Saxon, Caledonian, Celt, Gael, Goth, Norman, Northman, Persian, Prussian, Saxon, Teuton. 4 examples with Saxon and AngloSaxon tokens are registered in IC. In the group of demonyms in the dictionary there are 8 tokens: African, Asian, Asiatic, European, Nilotic, Occidental, Oriental, Transalpine, Siberian. Only 2 demonyms are recorded in the IC dictionary - European and Asian. From the words-demonyms (names of inhabitants of cities, districts of the city, etc.) in the dictionary 5 tokens are registered: Cockney, Corinthian, Neapolitan, Parisian, Venecian; in IC - only 1 token Venician; at the same time, they also tend to be Eurocentric. Micro-ethnonyms in the dictionary and IC ALDCE are not presented.

It is noteworthy that the ALDCE dictionary records only 3 ethnohybrids: Afro-Asian, German-Americans, Irish-Americans (the last two ethnonyms in the dictionary are called Hyphenated Americans). In addition, ALDCE contains tokens with components Anglo- and Sino-: Anglomania, Anglophil (e), Anglophobia, Sino-Chinese. Only the adjective Anglo-Saxon in the context of "the pristine simplicity of Anglo-Saxon days", which reflects the historical context, is registered in the ALDCE IC. The metaphorical and metonymic use of some ethnonyms is registered in the ALDCE dictionary. In the first case there is a phenomenon of stereotyping: Gypsy - 2 . (playfully) an attractive or mischievous girl or a woman, especially one with black, sparkling eyes. Turk - 2. (hum. Esp of a child) a lively uncontrollable person: You little Turk! In the second - the connections in reality between ethnonyms and the mentioned artefacts are registered: Born within the sounds of Bowbells - said of a true Cockney. Kilted regiments - regiments of Scottish soldiers wearing kilts as part of their uniform.

The sample material contains a small number of tokens denoting racial affiliation: Black, Caucasian, Negro, Negroid, Quadroon, Mulato, Whiteman, Latin races, as well as words that combine in their meaning racial affiliation and origin/place of residence: Creole, Nordic, Mestizo. Creole - a person of pure European descent in the West Indies or Spanish America; a person of mixed European and negro blood in the West Indies, Mauritius etc.

The ALDCE dictionary has registered tokens, which along with the ethnic component also have:

- reference to military topics (6 tokens):

Askari - a European-trained African native soldier.

Gendarme - (in France and some other countries, but not in GB or the USA) a member of military force employed in police duties.

Grenadier - (formerly) a soldier who threw grenades, now the G-s, the G-guard, the British infantry regiment.

Gurkha - a member of a ruling race in Nepal who became famous as soldiers in the British Indian army.

Sepoy - an Indian soldier in the British-Indian army before 1947. 
Zouave - a member of the French infantry corps originally formed of Algerians.

- religious reference (6 tokens):

Copt - an Egyptian Christian.

Fakir - a Muslim or Hindu beggar who is regarded as a holy man.

Parsee - a supporter of a religious system in India, the members being descended from Persians who settled in India in the 8th century.

Pharisee - a member of an ancient Jewish sect known for strict obedience to written laws and for pretensions to sanctity; (Small p) self-righteous person.

Rabbi - a teacher of the Jewish law; (A title of) a Jewish priest.

Scribe - (among the Jews in older times) a maker and keeper of records, a teacher of the Jewish law.

- social/caste reference (3 tokens): caste.

Outcaste - (in India) a person having lost or been expelled from, or not belonging to a

Pariah - (in India) a person of a low caste or of no caste; (Fig) a social outcast.

Untouchable - a member of the lowest caste in India.

-professional reference (often with bright gender component) (19 tokens):

Banian - a Hindu trader.

Dhobi - (in India) a man whose trade is washing clothes.

Dragoman - a guide or interpreter (in Arabic speaking countries).

Laskar - a seaman from the East Indies.

Majordomo - a chief steward in an Italian or Spanish princely household.

Minstrel - formerly called a 'nigger minstrel' - one of a company of public entertainers often with blackened faces, at fairs, race-meetings, and on the seashore at holiday resorts.

Moujik - a Russian peasant.

Muniteman - an American militiaman during the revolutionary period (ready for service in a minute's notice).

$\mathrm{Nabob}$ - (18th 3 use) a wealthy, luxury-loving person, esp. one returned to Gr. Bt. from India with a fortune.

Peon - (in Latin America) a farm worker, esp. one who is not wholly free.

Toreador - a Spanish bull-fighter (usually mounted on a horse).

Troubadour - a traveling poet and a singer in France and Italy, from 11th to 13th century.

Viking - any of Scandinavian sea-robbers who raided the coasts of Europe during the 8th, 9th and 1oth centuries.

Duenna - an elderly woman acting as a governess and companion in charge of girls (esp. In a Spanish family). 
Geisha - a Japanese girl or woman trained to entertain men by singing and dancing at parties etc.

Mammy - a Negro woman in charge of children.

Midinette - a Parisian shop girl, esp. a milliner's assistant.

Nautchgirl - a girl who takes part in a nautch (a performance by professional dancing-girls in Indonesia).

Odalisque - an Eastern female slave or a concubine (e.g. in a seraglio in older times).

In two cases of reference clarification of the word-ethnonym is conducted according to geographic sign:

Bedouin - an Arab, especially a nomad Arab living in the deserts of North Africa, Syria and Arabia.

Burgher - (old use) a citizen (esp. Of a Dutch or Flemish town).

The dictionary records the name of an ethnic group that combines several ethnic features: Boer - a Dutch South African.

The quantitative ratio of tokens is thus 1.5 times, which, compared to ALDCE data, where the ratio of 82 and 34 exotic words is 2.5 times, respectively, indicates not only an increase in interest in the external attributes of culture (food, clothing, national symbols, etc. ), but also about the desire to learn about the spiritual culture of different ethnic communities, which finds expression in national traditions and holidays, music, songs and dances, religious rites, literature, philosophical attitudes, and others.

Most of the exoticisms (158 units) are the realities of non-European nations and small nations (29 in total), including Arab, Australian, Brazilian, Caribbean, Chinese, Greek, Indonesian, Imdt, Japanese, Malaysian, Maori, Mexican, (Middle) Eastern, Nigerian, (North / West / Black) African, Pakistani, South / Latin / Native / African-American, (South / SE) Asian, (West) Indian, as well as the names of such regions as Haiti, Pacific Islands, South Africa, which also refer to representatives of non-European ethnic groups. The definitions of 72 exotic words contain the names of 14 European nations and ethnic groups: American, British, Czech, Dutch, French, German, Hungarian, Italian, Jew / Jewish, Polish, Spanish, Scottish, Russian, Swiss. Thus, the twofold predominance of exotic words denoting cultural artifacts of non-European nations and ethnic groups, which in turn also double the number of European nations and ethnic groups, is another indication of changes in the English language due to increased multicultural reflection in Englishspeaking society.

The group represented by the deninym South Asian has the largest representation among exotic words -27 exoticisms on various subjects, mainly the names of dishes and drinks. Further in frequency, the definitions of exoticism include the adjectives Chinese (20), Indian (16), Jewish (15), Japanese (15), and others. It can be assumed that these cultures are perceived by the English language consciousness as the most exotic and attractive. An analysis of OALD's vocabulary and illustrative contexts revealed a significantly greater number of ethno-labelled tokens than the 1963 edition of the ALDCE dictionary. If ethnonyms and ethnonyms-deriving adjectives used to denote European nations and ethnic groups were represented by 54 tokens in the ALDCE dictionary, only 27 tokens (i.e. almost twice as many) were recorded in the OALD dictionary: American, Briton, British, Canadian, Dutch, English, French, German, Greek, Grecian, Hebrew, Hebraic, Irish, Italian, Jew, Jewess, Jewish, Maltese, Portuguese, Russian, Scot, Scotch, Slav, Slavonic, Spanish, Swiss, Welsh. 
23 tokens registered in the ALDCE dictionary are unknown in OALD due to geopolitical (disintegration of states) and global ideological (departure from Eurocentrism) changes: Czech, Czechoslovak, Cyprian, Cypriot, Dane, Danish, Dutchman, Finn, Frenchman, Irishman, Irishwoman, Jugoslav, Netherlander, Norwegian, North countryman, Pole, Polish, Scotchman, Scotchwoman, Sicilian, Spaniard, Swede, Swedish. At the same time, the OALD dictionary presents a number of ethnonyms and ethnonyms-deriving adjectives that are not registered in ALDCE: Breton, Britisher, Englishman, Englishwoman, Gallic, Germanic, Hellene, Hellenistic, Jewiy, Slavic. Thus, a total of 37 ethno-labelled tokens denoting European nations and ethnic groups are recorded in the OALD. The names of non-European nations and ethnic groups are presented as words that match the sample material of the ALDCE dictionary - 17 units (Arab, Bushman, Chinese, Eskimo, Gypsy, Hindu / Hindoo, Indian, Japanese, Maori, Moor, Romany, Semite, Semitic, Sinhalese, Tamil, Turkish, Zulu) and ethnomarked tokens not registered in ALDCE - 13 units (Brazilian, Bengali, Cuban, Filipino, Inuit, Pakeha, Roma, including the names of little-known ethnic groups - Igbo, Hausa, Koori, Pygmy, Xhosa, Yorubd). A significant group of ethnonyms in the OALD dictionary are the names of the indigenous peoples of the North American continent - 23 tokens: Apache, Blackfoot, Cheyenne, Comanche, Cree, Creek, Crow, Hopi, Mohawk, Navajo (Navaho), Nez Perce, Ojibwa, Paiute, Pawnee, Pima, Pueblo, Seminole, Seneca, Shawnee, Shoshone, Sioux, Tlingit, Zuni, indicating their residence at a certain time, for example: Blackfoot - a member of Native American people, many of whom live in the US state of Montana or in Alberia in Canada. The ALDCE dictionary did not mention the names of indigenous groups. They were represented only by the hypernyms Indian and Red Indian.

Thus, the OALD pays much more attention to the lexicographic representation of nonEuropean nations and ethnic minorities. A total of 53 such tokens are registered in the OALD dictionary, which is 1.5 times more than in ALDCE. The IC presents 25 tokens (this is more than 2 times higher than ALDCE), as well as 59 cases of their use as illustrations/examples (also more than 2 times higher than ALDCE). The growth of quantitative and qualitative diversity of ethnonyms in the modern dictionary can be seen as evidence of the decline of Eurocentrism and intense multicultural reflection in modern English-speaking society, which confirms the definitions of the words Igbo, Hausa, Xhosa, Yoruba, for example: Igbo - a language spoken by the Igbo people of W. Africa, esp. in SE Nigeria.

The OALD dictionary presents a group of ethno-marked tokens, which can be attributed to micro-ethnonyms - the names of the inhabitants of a certain area (8 tokens), while in the ALDCE dictionary such tokens were not recorded:

Aberdonian - a person from Aberdeen in Scotland.

Cajim - a person of French origin from Louisiana, who speaks an old form of French, also called Cajun; connected with the Cajuns.

Catalan - a person who was born and lives in Catalonia.

Cornish - connected with Cornwall, its people, language or culture.

Geordie - a person from Tyneside in NE England.

Gujarati - a person from the state of Gujarat in Western India.

Highlander - a person who comes from the Scottish Highlands.

Tyke (inf) - a person from Yorkshire. 
In the group of words-historicisms in the OALD dictionary there are 9 ethnonyms and ethnonyms-deriving adjectives: Anglo-Saxon, Celt, Gothic, Israelite, Norman, Persian, Saxon, Trojan, Viking, which is slightly less than in the ALDCE dictionary (11 tokens).

The group of demonyms in the OALD dictionary is represented by 4 tokens: African, Asian, European, Oriental, while in the dictionary of the early edition 8 similar tokens are recorded.

From the words-demonyms (names of inhabitants of cities, districts of the city, etc.) in the dictionary OALD 6 tokens are registered, which (except Cockney) were recorded in the dictionary of 1963 edition:

Angelino - a person who lives in Los Angeles.

Brummie (inf) - a person from the city of Birmingham in England.

Cockney - a person from the East End of London.

East-Ender - a person from an area of East London traditionally connected with working people.

Londoner - a person from London in England.

Sconse - a person from Liverpool in NW England.

The ALDCE dictionary presents other words-demonyms in the amount of 5 tokens.

The following demonyms are registered in OALD: African (6), European (21), Asian (2), North American (1); in the contexts of ALDCE there are only 2 examples with the word European. The IC of the OALD dictionary presents the names of small nationalities such as, for example, Cajun (2), Zulu (1) and the names of the inhabitants of a certain area (Texan), i.e. such ethnonyms that can be refered to the category of "micro-ethnonyms", while in the IC of the dictionary ALDCE similar examples were not found. In IC of the OALD 4 tokens are registered belonging to the group of words-demonyms: Bostonian, Viennese, East-Ender, Berliner, while in IC of the ALDCE there is only one token from this group - Venician.

Thus, the number of ethnomarked tokens belonging to the categories of ethnochoronyms, microethnonyms, demonyms and historicisms differs slightly in the dictionaries of the two time sections, but differs significantly in the IC of the dictionaries. There is a tendency towards a more detailed representation of ethnicity at the micro level and coagulation - at the macro level, i.e. the level of detail of ethnic specifics and differences increases, which can also be interpreted as a consequence of multicultural reflection and departure from ethnocentrism. Another distinctive feature of the OALD dictionary, which reflects changes in the conceptualisation of ethnicity, is the formation of ethnohybrids by stems addition (sometimes truncated). The ALDCE dictionary contains only 3 similar tokens: Afro-Asian, German-Americans, Irish-Americans, while the OALD dictionary contains 14 ethnohybrids of this kind: African-American, African-Canadian, Afro-Asian, Afro-Caribbean, Amerasian, American Indian, Ameridian ((old- $f)=$ Native American), AsianAmerican, Centi'al-American, East-Indian, Eurasian, French-Canadian, Indo-Canadian, MiddleEuropean.

It is worth noting that in OALD the ethononyms-deriving adjectives British and Scottish are recorded in the definitions of 9 and 11 exotic words, respectively, the token English occurs only in 2 definitions, while the token Welsh is not represented at all. It can be assumed that the quantitative ratio of the tokens British and English may indicate an increase in the relevance of British national culture and ethnic identity, but in order to draw such a conclusion, further research is needed. 
Given that the words-exoticism have a "cultural" function, which signals a specific feature of the concept associated with this national culture, the concept of "ethnic" is increasingly close to the concept of "cultural", which in its turn contributes to the perception of ethnicity as a cultural construct. Dictionaries OALD and ALDCE present a group of ethno-labelled collocations of idiomatic nature. These are stable phrases with ethnonyms and ethnographic adjectives, which are either the names of organisations (the European Parliament) or which name household and social objects and phenomena associated in the English language consciousness with certain ethnic groups and nationalities.

Only 4 similar combinations are recorded in the ALDCE dictionary: Norfolk jacket, Turkish delight, Venetian blind-window, Turkish bath, while in the OALD dictionary this group of collocations is presented much more widely -68 phrases. Thus, the phraseological compatibility of the token American actualises the way of life and key values of culture as conceptual features of the American: American breakfast, American cheese, American football, American plan, the American League, the American dream, the American eagle. The word European is mainly used in collocations related to politics - that is, conceptualisation has a political focus, which is historically determined by social transformations associated with European integration: the European Commission, the European Parliament, the European plan, the European Union.

The most numerous idioms with the word French, their compatibility covers mainly the areas of fashion, cuisine and lifestyle French dressing, French fiy, French horn, French kiss, French letter, French door, French polish, French window, French press, French bean, French loaf, French stick, French bread, French braid, French plaid, French pleat, French toast, French twist. Stable combinations are formed with other ethnonyms and ethnonyms -deriving adjectives: Cornish Cream, Cornish pastry; Danish blue, Danish pastry; English breakfast, English horn, English muffin, English rose; Jew's harp; Mexican wave; Maltese cross; Nordic walking; Irish coffee, Irish stew; Russian doll, Russian roulette; Scotch broth, Scotch eggs, Swiss Army knife, Swiss ball, Swiss chard, Swiss cheese, Swiss roll; Turkish bath, Turkish coffee, Turkish delight; Welsh dresser, Welsh rarebit; some of them belong to the historical perspective: Indian corn, Indian ink, Indian summer, Indian rubber; Dutch barn, Dutch door, Dutch auction, Dutch courage, Dutch elm disease; Scotch bonnet, Scotch tape.

Only one stable combination has a direct anthroponomic reference. Based on metaphorical transference, this combination has a positive connotation: English rose - an attractive girl with fair skin and appearance that is thought to be typical of English people. Analysis of stable combinations with ethnonyms allows a clearer picture of the boundaries of ethnicity in the modern Englishspeaking world. In most cases, such idioms relate to the semantic sphere of "cooking" (American breakfast, American cheese, Danish blue, Danish pastry, English breakfast, English muffin, French dressing, French fry, French bean, French loaf, French stick, French bread, French toast, Irish stew, Scotch bonnet, Scotch broth, Scotch eggs, Swiss cheese, Swiss roll, Turkish delight, Welsh rarebit), "drinks" (Turkish coffee, Irish coffee), as well as "clothing and jewelry" (Indian corn, French braid, French plaid, French pleat, French twist), "house, furniture and interior items" (Dutch barn, Dutch door, French door, French polish, French window, Welsh dresser), "musical instruments" (French horn, English horn, Jew's harp), "games, sports and entertainment" (French kiss, French letter, Mexican wave, Nordic walking, Russian doll, Russian roulette, Swiss ball, Turkish bath).

According to the results of the research, the largest number of IC with ethnonyms in ALDCE is devoted to cultural topics ( 36 examples): "There is a firm exhibition of Chinese porcelain in the museum"; "My brother whom you met the other day has recently written a book on Indian art"; "The Italian dress materials are quite the thing this summer". Next in descending order are ICs on 
political topics (32 examples): "the British minister in Lima"; "the French embassy in London"; "nationalized Poles and Greeks in the USA"; on education (9): "if we compare British and American Universities"; "teach French history"; "write Chinese characters"; IC related to military (6): "the military conquest of the Arabs"; "the counties that were under the French rule"; "the colonization of North America by the British, Dutch and French"; economy (3): "The industrial revolution modified the whole structure of the English society"; "Does the country need some American uplift?" "Japanese goods are for the most part of good quality"; sports (3): "The English team has outplayed the Peruvians"; "The British champion was outpointed by the Mexican"; "The American boxer was properly beaten by the new world champion"; IC on gastronomic topics (3): "the Japanese diet of rice, vegetables and fish"; "the principal food of the people of Java".

The biggest number of IC, in which words-ethnonyms are used in the OALD, are devoted to art, culture, entertainment (64 examples): "a collection of Chinese jade"; "She's keen to learn about Japanese art"; "Do you know any other Latin American dances?". Next in descending order are the ICs on political issues (31): "The issue of joint statement by the French and German foreign ministers"; "The Foreign Minister held talks with his Chinese counterpart"; "The American electoral circus"; economic topics (24): "This deal is their first major inroad into the American market"; "the German practice of giving workers a say in how their company is run"; "The company is out to capture the Canadian market"); sports (24): "The French runner is coming up fast on the inside"; "The Australian in lane four is coming up from behind"; "The Dutch player will make his first appearance for Liverpool this Saturday"; gastronomic theme (17): "It is stronger in flavour than other Dutch cheeses"; "I'm not crazy about Chinese food"; T sampled the delights of Greek cooking for the first time"; military (12): "the German invasion of Poland of 1939"; "the French foreign legion"; "More British troops have been sent to the front"; education (5): "the British educational system"; "I must admit to a prejudice in favour of British universities"; "He's a Princeton-educated Texan"; mediarelated IR (4): "Unlike the American, the British press operates on the national scale"; "the American society of newspaper editors"; "a televised message from the President to the American people"; environmental issues (2): "the ecological footprint of the average Canadian"; "A number of British beaches failed to meet European standards of cleanliness".

\section{Discussion}

The theory of social identity was formed on the basis of the theopsychoanalytic socio-psychological concept of ego-identity by E. Erikson (1968), which became a classic. In "The Problem of EgoIdentity", published in 1959, E. Erikson (1968) wrote that the term identity expresses a relationship in which it simultaneously means constant similarity within oneself, that is, self-identity and the constant division of any what essential characteristics with others. Internal identity is a synthesis of an individual's awareness of his individuality (self) and at the same time belonging to a certain social, cultural community (Erikson, 1968). The process of identification and formation of identity is based on the cognitive framework (frame) "one's own - someone else's", through which information is selected that enters for further cognitive processing and as a result is formed into a certain structure. In other words, the process of identification is described by the concepts of "own", "other" and "foreign", where "other" is a more or less rational alternative to "own" (neutral assessment), and "foreign" reflects the perception of "not own" through prism of evaluation (negative evaluation) (Sergeeva, 2007).

For the purpose of theoretical analysis in the typology of identity there are personal, individual, collective, cultural, subcultural, gender and ethnic identity. Personal, individual and 
collective type of identity of the subject is the basis for further differentiation, resulting in other varieties. Ethnic identity is represented as a species in both personal and collective identity. In sociology, the concepts and theories of ethnic identity are grouped into two groups based on methodologically opposite approaches to the problem of ethnic substance: ontological (primordialist or essentialist) and functional (constructivist, instrumentalist) (Rybakov, 1998). The ontological approach assumes the presence of an ethnic substance that has a primordial, i.e. initial nature - either sociobiological or evolutionary-historical.

Proponents of the sociobiological direction interpret ethnicity as a somewhat objective, initial characteristic of humanity and believe that the awareness of group affiliation is embedded in the genetic code and is a product of early human evolution. Proponents of evolutionary historicism proceed from the recognition of ethnic communities as special material and spiritual entities based on the commonality of territory, economic life, language, culture and psychology. They interpret the ethnos as a historically formed in a given area a stable intergenerational group of people with not only common features but also relatively stable features of culture (including language) and psyche, as well as awareness of their unity and difference from all other similar entities (selfawareness) fixed in the self-name (ethnonym). In this concept, much attention is paid to ethnic identity as a criterion for classifying ethnic communities. According to the concept, not every group of people with a set of cultural characteristics is an ethnic group. Ethnos is definitely characterised by the antithesis of "we - they". Therefore, the ethnos represents only the cultural community of people who perceive themselves as such, distinguishing themselves from other similar communities. This awareness of members of the ethnos of their group unity is called ethnic selfconsciousness, the external manifestation of which is a common self-name (ethnonym) (Smythe \& Seidman, 1957).

In general, proponents of the ontological approach tend to view ethnic associations as real and long-standing groups with their own attributes, and ethnicity is considered a conservative force that preserves the mentality and behaviour of previous generations. Modern approaches within this tradition recognise the growing role of spiritual and organisational and political factors in the life of ethnic groups, which, however, does not cancel the objective content of patterns and trends in ethnic processes. A functional approach that combines constructivism and instrumentalism is characterised by the denial or disregard of ethnic substance.

Representatives of constructivism consider, as a rule, the external functional connections that arise in society in relation to the ethnic. Constructivists see ethnicity as a mental construct created by an individual in the process of building his cognitive picture of the world through the purposeful influence of external cultural creators from outside and which is later used as a tool in solving political and economic problems. According to the constructivist concept, ethnicity is not an essentialist (essential) category, but a mental construct, an "imposed" sociality rooted in myths, values, and symbols created by society and constantly changing. Accordingly, ethnicity appears as a historical quantity that contains nothing static and always assumes a new meaning (Smythe \& Seidman, 1957).

At the heart of the instrumentalist understanding of ethnicity is the socio-psychological theory of personality, communication, compensatory needs. Ethnicity, as if in a latent state, is brought to life and used for social mobility, overcoming competition, domination and social control, mutual services and solidarity, for political mobilization and for achieving hedonistic aspirations (Bell, 1975). From an instrumentalist point of view, it is generally accepted that ethnicity can be better understood as "the choice of those individuals who would otherwise choose other group associations as a means of achieving power and privilege" (Bell, 1975). The mobilisation of 
the group for active action emphasises the role of leaders who have chosen ethnicity as a "strategic point" in the realisation of common aspirations to obtain political or other compensation for low social status (Bell, 1975).

The starting points of non-essentialist concepts are important for this study. The functional approach more accurately and deeply reveals the essential changes taking place with ethnic communities in the modern world. The constructivist paradigm states quite clearly that some very important elements of ethnicity are amenable to social construction. Proponents of functionalism rightly point to the importance of mass manipulation of ethnic identity, the existence of a large practice of pragmatic use of ethnicity by politicians, and so on. At the same time, modern domestic science rightly emphasises the advantages of an integrated approach to the interpretation of this category, which contributes to the formation of the notion of ethnicity and ethnos both without ontologising ethnicity primordialism and without extreme manifestations of constructivism focused on subjective production of the social world.

The most important trends in the development of identity theory in the postmodern world, significant in the linguistic consideration of ethnicity and ethnocultural identity, are revealed in the works of sociologists. K. Hall (1995), for example, emphasises that if earlier ethnicity was tied to "rigid" structures (class, ethnos, gender, etc.), then at the present stage it is determined based on mobile, flexible criteria. He distinguishes between "attributed" and "conscious" identity, noting that in present, identity is increasingly transformed from a state into a reflexive process; emphasises that current identity is an ever-changing identity, and points to a postmodern phenomenon such as "identity ritualisation" (Hall, 1995). In the study of ethnicity, including issues of interethnic interaction, in domestic science today remains predominant historical and ethnographic approach. The concept of ethnicity for many researchers implies the existence of homogeneous functional and static characteristics that distinguish one group from others with a different set of similar characteristics. The modern constructivist concept of ethnicity questions such a view of cultural identity, paying attention primarily to its procedural (socially constructed) nature, the mobile and multicultural nature of modern societies, the practical absence of cultural isolates.

As noted above, in domestic linguistics, the study of ethnicity from a constructivist standpoint is much narrower than in foreign, where such an approach is most common today. In the context of the transition to the information society and the development of the idea of multiculturalism, foreign researchers discuss, among others, such terms as "transcendent ethnicity" and "after identity" (Warnke, 2008). The concept of ethnicity is increasingly used to describe the active processes of association or division of people as a result of the mechanisms of identification - identification with a particular community, the emphasis on cultural specifics, values, etc.

According to the latest census in the UK, the current generation does not perceive belonging to a particular ethnic group as something obligatory and permanent: one million young people identify themselves as members of a mixed race. By 2015, the mixed race is likely to become the largest national minority in the UK. In other countries and regions (USA, Mexico, Brazil, Canada), the percentage of the population belonging to the mixed race ranges from 1.6 to $38.5 \%$. According to the 2010 census, the country is home to more than 9 million Americans of multi-ethnic descent, or $2.9 \%$ of the US population. The most numerous groups of representatives of the mixed race are: "representatives of white and black race" (White and Black - 1.8 million - 20.4\%), "representatives of white and other races" (White and borne Other Race - 41.7 million - 19.3\%), "Representatives of the white and Asian race" (White and Asian - 1.6 million - 18\%), "representatives of the white race and the indigenous population of America / indigenous population of Alaska" (White and American Indian and Alaska Native -1.4 million - 15.9\%), representatives of three or more races (o.74 million 
- 8.3\%). The combination of different ethnic characteristics (biological, but to a greater extent linguistic and cultural) is becoming more common and is of increasing interest.

As a result of the described processes, ethnicity as a construct is increasingly subject to fragmentation. Individual language signs and artefacts - melodies, clothing, language, food acquire symbolic values, replacing the essential features of ethnicity. Examples are the widespread fascination with ethnic cuisine (Chinese, Indian, Turkish and other restaurants in different countries), the principles of placing furniture in the house and the use of amulets according to Chinese Feng shui, elements of ethnic style in clothing, music, etc. Developing A. Pennycook's (2004) theory of linguistic and cultural performativity, J. Maher (2010) introduces new terms "metroethnicity" and "metrolanguage" to denote the means of constructing a "facilitated" ethnic identity - playful, flexible, able to live in any what a big city (Pennycook, 2004, Maher, 2010).

Metroethnicity is something that arises in a specific situation, is mobile in time and space, has different contextual meanings and evokes different emotions (Maher, 2010). The term "metro" in this case has a number of meanings that indicate phenomena that are outside the usual understanding of language and ethnicity, describes the hidden (underground) rather than the obvious (overground) (Maher, 2010). Metroethnicity is perceived as blurring the boundaries between ethnic groups and is a special form of hybridisation and fragmentation. In order to give a Chinese name to a new-born, it is not necessary to be of Chinese origin and even speak Chinese. It is possible to just borrow a liked name, something that is beautiful, fashionable, aesthetically pleasing. In addition to the external attributes of ethnicity, spiritual values can be borrowed. For example, in the Hollywood film "The Last Samurai", the protagonist - an American by birth - not only dresses in the form of a Japanese warrior, but also adopts the values of another culture.

Speaking of metroethnicity, it seems appropriate to draw a parallel between ethnicity and gender. Based on the constructivist approach, foreign authors (Hall, 1995) question the notion of gender as an a priori social category and treat social identity and gender identity as social constructs, rather than "predetermined" social parameters of human classification. Gender in this interpretation is a product of social interaction (occurs in communication). The focus of the study is on how individuals create a gender identity in interaction with other people. In other words, the emphasis is on the dynamic aspects of interaction, where language is the most important creative resource, and linguistic choice can emphasise certain aspects of social (gender) identity in a particular situation - as a reaction to the audience and/or situation (Grytsenko, 2004).

Ethnicity, and even more metroethnicity, are also products of socio-cultural construction. In this case, metroethnicity is not just a combination of two components (ethnicity A and B), it is a "remix" that already has other, modified, rethought characteristics, formed based on the interaction of identities $\mathrm{A}$ and $\mathrm{B}$, environmental influences, language, gastronomic habits, fashion and personal perception of an individual, which is flexible and subject to constant change. In the phenomenon of metroethnicity, according to A. Rattansi (1992), there is a special kind of reconceptualisation of "culture". The point is that "ethnicity ... refers to the awareness of culture, its use as a resource and at the same time part of it" (Rattansi, 1992).

D.B. Willis and S. Murphy-Shigematsu (2008) directly link this phenomenon with the process of globalization, which leads to a mixture of cultural and politico-economic components, hybridity, the emergence of so-called "translocal creolised cultures". In relation to ethnicity, the term "hybridity" is used to denote "bordering" or contact points of diasporas, as well as to describe a wide range of social and cultural phenomena, including the mixing of two or more cultures (Hutnyk, 2005). S. Hall (1988) connects hybridity with the idea of "new ethnicities", which expresses the desire to create non-static and non-essentialist approaches to ethnic culture. He argues that 
identity, through hybridity, is realised jointly through differences, but not in opposition to them (Hall, 1990). Language plays a key role here (Hall, 1988). For example, African students at a Toronto school prefer not to position themselves as ethnic Sudanese or Nigerians, but identify with Black, using "their" language (Black Stylized English (BSE)) for (self) identification according to race distribution adopted in North American society (Ibrahim, 1999). B. Bailey (2000) describes the language practices of Dominican students in the United States who use the spoken form of African American English vernacular to express solidarity with their African-American peers (Bailey, 200o), while communicating with each other in Spanish to create their own group identity, different from other students (Pavlenko \& Norton, 2007). A. Kirilina (2012) examines the language situation in Germany, where children of migrants who have received schooling in German use it in combination with their native language. She concludes that "mixed language is chosen consciously to construct a group identity, which includes ethnicity" (Kirilina, 2012). As can be seen, the search for the roots and origins necessary for "new ethnicities" is not simply a matter of truncating an identity formed on the basis of origin. Ethnicity changes in the diasporic space, in interaction with both the historical homeland and the society in which the group is integrated.

Hybrid forms of ethnicity (as well as traditional ethnicity) are based on the recognition of the role of culture in determining ethnic identity. It means the preservation of any part of the cultural heritage (continuity and coherence), which allows for cultural (self) identification, and then combined with other forms to create a new organic whole (Anthias, 2001). The approach to ethnicity outside the traditional cultural types and the recognition of the possibility of "ethnic drift" allows considering "not a person in ethnicity, but ethnicity in a person." An ethnic community is a community based on cultural self-identification with other communities with which it has fundamental ties. Ethnicity is formed and exists in the context of the social experience with which people are associated or with which they identify with others as members of a particular ethnic group (Tishkov, 2003).

The current epoch is called the epoch of reflexive modernism, which is characterised by detraditionalisation, when a person begins to comprehend his place and position in society, selfdetermining in relation to the set of existing identities. M. Castells (1997) raises the question of the relationship between globalisation and identity, which, in his opinion, contradict each other in the context of integration and individualisation. Z. Bauman (1998), on the other hand, considers identity to be the prism through which man looks at the world today, and emphasises that globalisation not only does not remove the problem of identity, but sometimes exacerbates it, making it the most important problem of postmodernity. The concept of multiculturalism as a methodological basis of modern ethnosociological and anthropological research substantiates ethnicity as a "moving and changing concept", "a form of social organisation of cultural differences" (Tishkov, 2003).

The work of Chinese researcher W.S.E. Lam (2004) analyses code-switching as a way of constructing a new ethnic identity for Hong Kong Chartroom users - Chinese immigrants to the United States and their friends around the world (Lam ,2004). A combination of English vocabulary and grammatical constructions with emotionally coloured Latinised Chinese words, the use of numbers that are homonymous Chinese words in sound, as well as specific Chinese markers of discourse - particles that express interest, compassion, motivation, etc. - all these language tools have created a new collective ethnic identity of bilingual Chinese emigrants, which distinguishes them from other users of the World Wide Web - both English-speaking Americans and Cantonesespeaking Chinese. 
In emotional discourse - informal communication of bilingual immigrants (Pavlenko \& Norton, 2007) - metroethnicity and metrolanguage are presented in the form of parents' use of resources of different languages in communication with children and other family members to express love, tenderness, praise, disapproval, etc. The key principle of choice is individual feelings of emotionality of a language, memories from one's own childhood, etc. The phrase uttered in the native language is most often characterised as "sincere", "appropriate", "natural", in a situation where the expression in the language of the new homeland may sound "wrong", "artificial", "unreasonable", "funny". The developed morphological system of the native language, the variety of diminutive-loving suffixes in Ukrainian, Spanish, French and other languages in comparison with English allow to express tenderness, care, admiration, etc. with the help of emotionally coloured occasional combinations and language hybrids, the choice is similarly made to express condemnation, dissatisfaction, prohibition.

The study revealed an increase in the number of ethnic anthroponyms that combine ethnicity as a parameter of social identity with other characteristics of the individual: gender, professional, socio-caste reference. The conceptual features of ethnicity in the English-speaking language consciousness at the present stage includes the sphere of religious-status relations. Linguistic confirmation of the strengthening of the ideology of tolerance and the discourse of political correctness in modern English-speaking society is the decrease in the number of stereotypical representations of ethnic groups in illustrative contexts, the appearance in the dictionary of politically correct names of ethnic minorities.

In contrast to the essentialist understanding of ethnicity as an immanent immutable entity characteristic of the middle of the $20^{\text {th }}$ century, in the modern English-language picture of the world, ethnicity is conceptualised as a cultural construct. Ethnicity becomes a means of accentuating cultural specificity, which is expressed in a twofold increase in the number of exotic words in the OALD dictionary, compared to the ALDCE dictionary, the use of ethno-marked tokens as an attribute to cultural artefacts in the IC of the OALD dictionary. The study confirmed that ethnicity is a dynamic product of the discourse of the era, constructed in different types of texts. Taking into account ethnicity in the linguistic description contributes to a fuller understanding of the English-language picture of the world, deepens scientific ideas about the interaction of ideology, language, culture.

\section{Conclusions}

According to the results of the study, the largest number of IC with ethnonyms in the ALDCE is devoted to cultural topics (36 examples). Next on the descending are IC on political topics (32 examples); on the topic of education (9); IC related to military (6); economy (3); sports (3); IC on gastronomic topics (3). As can be seen, although the range of ethno-relevant fragments of the English language is quite wide, the most representative here is the sphere of culture and politics, which is fully consistent with the above data on key conceptual features of ethnicity. Thus, the results of the analysis allow concluding that the representation of ethnicity in the ALDCE dictionary is presented essentialistically, taking into account biological (racial) and geographical characteristics, as well as professional reference, which is fully consistent with the philosophy and ideology of the period.

The largest number of IC, which use ethnonyms in the OALD, is devoted to the topic of art, culture and entertainment (64 examples). Next in descending order are the ICs on political issues (31); economic (24); sports (24); gastronomic topics (17); military (12); education (5); IC related to 
the media (4); environmental issues (2). Thus, IC of the OALD indicate that in modern communicative practice is becoming more widespread ethnic labelling of music, traditions, cultural artefacts, gastronomic sphere, etc.: Asian / African / Arabic / Indian music, African culture, Egyptian divinities, an Egyptian mummy, Jamaican reggae music, Creole cookery, Cajun cuisine, Cantonese cooking, the Chinese cult of ancestor worship, the exotic sounds of Japanese instruments, the Moorish architecture, Chinese food. In this case, the ethnic feature becomes a means of accentuating the cultural specificity, attractive for its uniqueness, exoticism, a means of meeting aesthetic needs. The study showed that the construction of ethnicity in different types of English-language discursive practices corresponds to the basic principles that characterise the development of the modern socio-constructivist paradigm: the interpretation of language activity as a social practice; the concept of language as a mobile resource, background and tool for constructing social reality and relationships; recognition of the historicity and ideology of ethnicity, its social and cultural conditionality.

\section{References}

Anthias, F. (2001). New hybridities, old concepts: The limits of "culture". Ethnic and Racial Studies, 24(4), 619-641.

Bailey, B. (2000). Language and negotiation of ethnic/racial identity among Dominican Americans. Language in Society, 29, 555-582.

Bauman, Z. (1998). Globalization: The human consequences. Cambridge: Polity Press.

Bell, D. (1975). Ethnicity and social change. In: N. Glazer, \& D. Moynihan (Eds.), Ethnicity: Theory and experience. Cambridge: Harvard University Press. 141-174

Castells, M. (1997) The power of identity (The information age: Economy, society and culture). Oxford: Wiley-Blackwell.

Erikson, E.H. (1968). Psychosocial identity. In: D.L. Sills (Ed.), International Encyclopedia of Social Sciences. New York: Macmillan. 61-65.

Grosheva, G.V. (2006). Categories of ethnos and ethnicity in a modern scientific discourse. Tomsk State Pedagogical University Bulletin, 1(52), 104-109.

Grytsenko, P. (2004). Ethnolinguistics. In: V.M. Rusanivsky, O.O. Taranenko, \& M.P. Zyablyuk (Eds.), Ukrainian language: Encyclopedia. Kyiv: Publishing House "Ukrainian encyclopedia named after Bazhan". 178-179.

Hall, K. (1995). Lip service on the fantasy line. In: K. Hall, \& M. Bucholtz (Eds.), Gender articulated: Language and the socially constructed self. New York: Oxford University Press. 186-216.

Hall, S. (1988). New ethnicities. In: K. Mesner (Ed.), Black film, British cinema. London: Institute of Contemporary Arts. 27-30.

Hall, S. (1990). Cultural identity and diaspora. In: J. Rutherford (Ed.), Identity: Community, culture, difference. London: Lawrence \& Wishart. 222-237.

Hornby, A.S. (1963). The advanced learner's dictionary of current English. London: Oxford University Press.

Hornby, A.S. (2010). Oxford advanced learner's dictionary of current English. Oxford: Oxford University Press.

Hutnyk, J. (2005). Hybridity. Ethnic and Racial Studies, 28(1), 79-102.

Ibrahim, A. (1999). Becoming black: Rap and hip-hop, race, gender, identity and the politics of ESL 
learning. TESOL Quarterly, 3(33), 349-369.

Kirilina, A.V. (2012). German language space at the beginning of the XXI century. Bulletin of Nizhny Novgorod State Linguistic University named after Dobrolyubov, 19, 34-42.

Lam, W.S.E. (2004). Second language socialization in a bilingual chat room: global and local considerations. Language Learning \& Technology, 8(3), 44-65.

Maher, J.C. (2010). Metroethnicities and metrolanguages. In: N. Coupland (Ed.), The handbook of language and globalization. Oxford: Wiley-Blackwell. 575-591.

Pavlenko, A. \& Norton, B. (2007). Imagined communities, identity, and English language learning. In: J. Cummins, and C. Davison (Eds.), Kluwer handbook of English language teaching Dordrecht: Springer. 669-68o.

Pennycook, A. (2004). Performativity and language studies. Critical Inquiry in Language Studies, 1(1), 1-26.

Rattansi, A. (1992). Changing the subject? Racism, culture and education. In: J. Donald, \& A. Rattansi (Eds.), Race, culture and difference. London: Sage in association with the Open University. 11-48.

Rybakov, S.E. (1998). On the concept of "ethos": The philosophical and anthropological aspect. Ethnographic Review, 6, 3-15

Sergeeva, M.V. (2007). Dynamics of gender representations in British defining lexicography. Nizhny Novgorod: Linguistics University of Nizhny Novgorod.

Smythe, H.H. \& Seidman, M. (1957). Name calling: A Significant Factor in Human Relations. Journal of Human Relations, 6, 71-77.

Tishkov, V.A. (2003). Requiem for ethnos: the study of social and cultural anthropology. Moscow: Nauka.

Warnke, G. (2008). After identity: Rethinking race, sex and gender. Cambridge: Cambridge University Press.

Willis, D.B. \& Murphy-Shigematsu, S. (2008). Transcultural Japan: At the Borderlands of race, gender, and identity. London: Routledge. 